\title{
A VIABILIDADE DE INCIDÊNCIA DA TEORIA DA EMPRESA NO DESPORTO
}

\section{LA VIABILIDAD DE LA APLICACIÓN DE LA TEORIA DE LA EMPRESA EN EL DEPORTE}

\author{
${ }^{1}$ Veronica Lagassi
}

\section{RESUMO}

O direito e incentivo ao desporto terminam por ser um direito fundamental. Esse raciocínio advém do fato de que sua prática propicia a melhoria da saúde mental e física. No entanto, apesar de possuir destaque constitucional e estar diretamente ligado à manutenção do direito à saúde e à vida, por inúmeras vezes, recebemos a notícia de que uma determinada associação desportiva passa por dificuldades financeiras e eventualmente, corre o risco de encerrar suas atividades. Será este o problema que iremos trabalhar, no sentido de defender a adoção da teoria da empresa no desporto como meio hábil para reverter o problema.

Palavras-chave: Palavras-chaves: desporto, Teoria da empresa, Direitos fundamentais

\section{RESUMEN}

El derecho y estímulo al deporte son un derecho fundamental. Ese raciocinio sucede del hecho de que su práctica propicia una mejora en la salud mental y física. Sin embargo, aunque sea notablemente ligado a manutención del derecho constitucional a la salud y la vida, por inúmeras veces, recibimos la noticia de que una determinada asociación deportiva pasa por dificuldades financieras y al fin y al cabo, tienen el risco de encerrar su lid. És ese el problema que iremos trabajar para defender la aplicación de la teoria de la empresa en el desporto como medio de solución del problema.

Palabras-claves: Deporto, Teoria de la empresa, Derechos fundamentales

\footnotetext{
1 Doutora em Direito pela Universidade Estácio de Sá, UNESA, Brasil. Professora do Grupo IBMEC, (Brasil). E-mail: vlagassi@hotmail.com.
} 


\section{INTRODUÇÃO}

Previsto no título VIII, da Constituição Federal Brasileira e topograficamente unido à educação e à cultura no capítulo III do supracitado título, o incentivo ao desporto é dever do Estado e direito de todos. Na Constituição Federal, ele não só aparece como algo a ser praticado como forma de lazer, mas também deve ser exaltado pelo simples fato de estar diretamente implicado com a saúde física e mental da população.

O incentivo e a adoção da prática de esportes é, muitas vezes, a diferença que irá definir a boa saúde de um cidadão e consequentemente, o menor dispêndio estatal com os custos de manutenção de hospitais e medicamentos.

Com base nisso, o presente trabalho tem por fim o de perquirir um meio efetivo para solucionar um problema recorrente que corresponde à dificuldade financeira enfrentada pelo principal ator do desporto, o clube. De personalidade jurídica normalmente concebida sob a forma de uma "associação", o clube ou associação recreativa tem a elaboração de seu estatuto social concebido a partir dos ditames previstos no artigo 53 e seguintes, do Código Civil Brasileiro.

Diante disso, a partir da materialização do clube sob essa forma de constituição da personalidade jurídica resta claro no art. 53, do CC/02, a ausência de finalidade econômica. Entretanto, na prática, esta ausência é duramente sentida quer seja ante a carência de investimento, quer seja pela falta ou inexperiência na gestão. Enfim, o presente trabalho busca demonstrar como a adoção da teoria da empresa pode contribuir no sentido de evitar que o incentivo e exaltação ao desporto, não corram o risco de se tornar "letra morta" na Constituição Federal Brasileira e por via de consequência, causar uma melhoria na qualidade de vida da população. Para tanto, traçamos um paralelo com a aplicabilidade dos principais institutos advindos da adoção da teoria da empresa como meio de comprovar a viabilidade de sua adoção. Utilizamos como nosso "modelo-piloto" os clubes de futebol, porém nada impede a sua divagação para outros esportes até porque, normalmente, um mesmo clube os oferece.

O método de pesquisa utilizado foi exclusivamente o bibliográfico, sob o qual fizemos uso de obras de Direito Empresarial e Desportivo no intuito de permear todo o tema a partir da interdisciplinaridade. Além disso, foi também feito uso da legislação pátria. 


\section{ASSOCIAÇÃO “VERSUS” TEORIA DA EMPRESA E O DESPORTO.}

Antes de tratar do tema "associação" para sua adequada compreensão, há que se dar um passo atrás a fim de resgatarmos a concepção da personalidade jurídica. Instituto este, que surge para legalmente legitimar a união de um grupo de pessoas para obtenção de um fim comum. Inúmeras foram as teorias ${ }^{1}$ criadas para sua fundamentação, porém a concepção moderna da personalidade jurídica adotou a teoria alemã. Ao tratar do tema o renomado Professor Alexandre Ferreira de Assunção Alves defende que os doutrinadores alemães "ao sistematizarem a matéria

civil, preocuparam-se em elaborar uma teoria que pudesse ser aplicada em qualquer ramo do Direito, considerando a existência de sujeitos distintos da pessoa natural e lhes atribuindo a titularidade de direitos subjetivos ${ }^{2} \%$. Fato que se ratifica por intermédio da aplicação do Princípio da Autonomia Patrimonial, o qual preceitua que os direitos e obrigações da pessoa jurídica não se confundem com as pessoas ${ }^{3}$ que a constituíram.

A pessoa jurídica a ser constituída pode ser de Direito Público ou Privado, nos termos do que dispõe o art. 40, do Código Civil Brasileiro. As de Direito Público subdividem-se ainda em: pessoas jurídicas de direito público interno e externo. Ao passo que, as pessoas jurídicas de Direito Privado ante ao que dispõe o art. 44, do Código Civil Brasileiro, podem ser constituídas sob a forma de associações, sociedades, fundações, organizações religiosas, partidos políticos, empresas individuais de responsabilidade limitada, dentre outras. Pois, conforme bem observa José Eduardo Sabo Paes o rol do supracitado artigo é exemplificativo e não exaustivo, existindo outras pessoas jurídicas de direito privado como, por exemplo, os sindicatos, as federações ou os serviços sociais autônomos 4

\footnotetext{
${ }^{1}$ PAES vai citar em sua obra: a teoria da ficção legal, a da personalidade jurídica como realidade objetiva, a da personalidade jurídica como realidade técnica e a institucionalista de Hauriou. (PAES, José Eduardo Sabo. Fundações, Associações e Entidades de Interesse Civil. $8^{a}$ Edição. Rio de Janeiro: Forense, 2013. P.04).

2 ALVES, Alexandre Ferreira de Assunção. A Pessoa Jurídica e os Direitos da Personalidade. Rio de Janeiro: Renovar,1998. P.9.

3 O termo "pessoa" é usado propositalmente porque dependendo da modalidade e espécie de pessoa jurídica constituída poderemos tanto ter pessoas físicas ou jurídicas a constituindo.

${ }^{4}$ PAES, José Eduardo Sabo. Fundações, Associações e Entidades de Interesse Civil. 8 a Edição. Rio de Janeiro: orense, 2013. P. 7.
} 
Outro ponto importante é saber que independente da natureza jurídica a existência legal da personalidade jurídica tem início com o registro de seus atos constitutivos em cartório de registro próprio, podendo preceder ou não de autorização ou aprovação do Poder Público.

Após toda essa preconcepção da personalidade jurídica, passemos agora a tratar de uma de suas modalidades em especifico, qual seja, a associação. Para tanto, iremos fazer uso da definição trazida por Paes, a saber:

Associação é uma modalidade de agrupamento dotada de personalidade jurídica, sendo pessoa jurídica de direito privado voltada à realização de interesses dos seus associados ou de uma finalidade de interesse social, cuja existência legal surge com a inscrição de seu estatuto, em forma pública ou particular, no registro competente, desde que satisfeitos os requisitos legais (CC, art. 45), que ela tenha objetivo licito e esteja regularmente organizada ${ }^{5}$.

Embora também sejam uma modalidade de agrupamento de pessoas, as associações distinguem-se das sociedades ante a incessante busca pelo "lucro" existente na segunda. No entanto, isso não implica em dizer que uma associação não possa também buscar à obtenção de lucro, porém desde que o mesmo não seja repartido entre seus associados, mas sim utilizado em proveito próprio da associação. Tal como defende Paes:

A associação não se desnaturaliza mesmo que realize negócios para manter ou aumentar o seu patrimônio, contudo, não pode proporcionar ganhos aos associados, por exemplo, associação esportiva que vende aos seus membros uniformes, alimentos, bolas, raquetes, etc. embora isso traga, como consequência, lucro para a entidade ${ }^{6}$.

É justamente a partir deste entendimento que defendemos a viabilidade de adoção da teoria da empresa e consequentemente, dos demais institutos que a partir de sua adoção são extremamente úteis à superação da crise por parte de alguns clubes.

O desporto está previsto na Constituição Federal e regulado a partir da Lei no 9.615/98, que no caput, do art. $1^{\circ}$, dispõe: $O$ desporto brasileiro abrange práticas formais e não-formais $e$ obedece às normas gerais desta Lei, inspirado nos fundamentos constitucionais do Estado Democrático de Direito. Mais adiante, no art. $2^{\circ}$, caput, da supracitada lei, temos a ratificação infraconstitucional de sua condição de direito fundamental, a saber:

Art. 2o O desporto, como direito individual, tem como base os princípios:

I - da soberania, caracterizado pela supremacia nacional na organização da prática desportiva;

II - da autonomia, definido pela faculdade e liberdade de pessoas físicas e jurídicas organizarem-se para a prática desportiva;

\footnotetext{
${ }^{5}$ Idem citação anterior, p. 14.

${ }^{6}$ Ib idem, p. 16.
} 
III - da democratização, garantido em condições de acesso às atividades desportivas sem quaisquer distinções ou formas de discriminação;

IV - da liberdade, expresso pela livre prática do desporto, de acordo com a capacidade e interesse de cada um, associando-se ou não a entidade do setor;

$\mathrm{V}$ - do direito social, caracterizado pelo dever do Estado em fomentar as práticas desportivas formais e não-formais;

VI - da diferenciação, consubstanciado no tratamento específico dado ao desporto profissional e não-profissional;

VII - da identidade nacional, refletido na proteção e incentivo às manifestações desportivas de criação nacional;

VIII - da educação, voltado para o desenvolvimento integral do homem como ser autônomo e participante, e fomentado por meio da prioridade dos recursos públicos ao desporto educacional;

IX - da qualidade, assegurado pela valorização dos resultados desportivos, educativos e dos relacionados à cidadania e ao desenvolvimento físico e moral;

$X$ - da descentralização, consubstanciado na organização e funcionamento harmônicos de sistemas desportivos diferenciados e autônomos para os níveis federal, estadual, distrital e municipal;

XI - da segurança, propiciado ao praticante de qualquer modalidade desportiva, quanto a sua integridade física, mental ou sensorial;

XII - da eficiência, obtido por meio do estímulo à competência desportiva e administrativa.

Nesse sentido, sustenta Gustavo Delbin ser o desporto um direito público e subjetivo, ou seja, é conferido pela Constituição aos indivíduos, contra o Estado, que tem o dever de promover, incentivar e proteger tal direito, conforme preceituam o artigo $5^{\circ}$, XXVIII, a, e o artigo 24, IX, da $\mathrm{CF} / 88^{7}$.

Até porque, está o desporto diretamente atrelado ao desenvolvimento humano, pelo fato de propiciar melhorias em sua qualidade de vida no que tange à saúde, educação e à cultura. Entendimento ratificado por Martinho Neves Miranda que ao tratar do desporto vai defender que essa atividade possui inegável valor para o desenvolvimento do ser humano, constituindo-se em um poderoso instrumento de aperfeiçoamento educacional e profícua ferramenta de consolidação da cidadania e afirmação da própria sociedade ${ }^{8}$.

Há ainda quem defenda que o desporto estaria também diretamente ligado à cultura de um povo. É o caso, por exemplo, de Celso Bastos:

A prática desportiva não é algo decorrente da natureza instintiva do homem, mas sim de toda uma história - neste sentido, apresenta-se unido à natureza cultural a qual já se fez menção. É por isto que há países que se esmeram e se destacam em determinada categoria esportiva, o que demonstra que o desporto é nitidamente atrelado à cultura de um povo que o pratica e, por outro lado, é uma manifestação da cultura desse povo ${ }^{9}$.

\footnotetext{
${ }^{7}$ DELBIN, Gustavo. SILVA, Rodrigo Ferreira da Costa. GRAICHE, Ricardo. Elementos do Direito Desportivo. São Paulo: Quartier Latin, 2008. P. 21.

${ }^{8}$ MIRANDA, Martinho Neves. O Direito no Desporto. Rio de Janeiro: Lumen Juris, 2007. P. 07.

${ }^{9}$ BASTOS, Celso. Justiça desportiva e defesa da ordem jurídica. Cadernos de Direito Constitucional e Ciência Política. São Paulo, vol. 6, no 25. out/dez. 1998. P.269.
} 
Como prenuncio o parágrafo único, do artigo $2^{\circ}$, da Lei $n^{\circ} 9615 / 98$, determina:

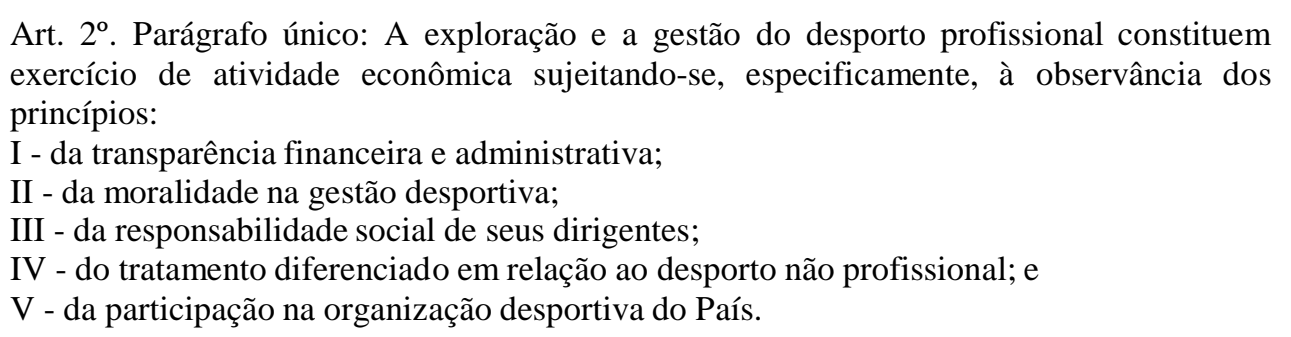

Notem que a própria Lei $n^{\circ}$ 9615/98 no texto acima transcrito já dá azo à adoção da Teoria da Empresa. Fato que igualmente ocorre no disposto no art.27, da referida Lei, a saber:

Art. 27. As entidades de prática desportiva participantes de competições profissionais e as entidades de administração de desporto ou ligas em que se organizarem, independentemente da forma jurídica adotada, sujeitam os bens particulares de seus dirigentes ao disposto no art. 50 da Lei no 10.406, de 10 de janeiro de 2002, além das sanções e responsabilidades previstas no caput do art. 1.017 da Lei no 10.406 , de 10 de janeiro de 2002, na hipótese de aplicarem créditos ou bens sociais da entidade desportiva em proveito próprio ou de terceiros.

Observe que por interpretação literal do artigo acima transcrito, é possível a constituição de um clube sob outra forma de personalidade jurídica distinta da associação, que é a modalidade comumente adotada para sua constituição. E como se não bastasse a possibilidade de constituição de um clube já sob a modalidade de sociedade, nada o impede de que após constituído possa deixar de ser uma associação e vir a transformar-se em uma sociedade.

A transformação é o meio pelo qual uma pessoa jurídica passa de uma espécie para outra sem que seja necessário fazer a sua liquidação ou dissolução. Essa possibilidade de conversão da associação em outra forma de personalidade jurídica é amplamente defendida por Paes que ressalta a transformação de associações em outras formas tem aceitação no Ordenamento Jurídico brasileiro, inclusive com a previsão expressa em lei para as entidades educacionais, conforme previsão do art. $7^{\circ}-A$, da Lei $n^{o} 9131 / 95^{10}$. Nos demais casos a transformação está prevista no Código Civil/02 a partir do art. 113, que dispõe: $O$ ato de transformação independe de dissolução ou liquidação da sociedade, e obedecerá aos preceitos reguladores da constituição e inscrição próprios do tipo em que vai converter-se.

Insta destacar, que o artigo acima transcrito está localizado topograficamente no Código no Livro II da Parte Especial, que é expressamente aplicável às associações por força do que dispõe o

\footnotetext{
${ }^{10}$ PAES, José Eduardo Sabo. Fundações, Associações e Entidades de Interesse Civil. $8^{\mathbf{a}}$ Edição. Rio de Janeiro: Forense, 2013 P. 460.
} 
art. $44, \S 2^{\circ}$, do próprio Código Civil. Portanto, impedimento legal não há para realização de uma transformação por uma associação.

Mas, apesar de todo o respaldo legal para a constituição ou transformação de um clube em sociedade ou mais especificamente, em sociedade empresária tal fato não ocorre no Brasil na prática. Além disso, juridicamente não esperamos que isso ocorra posto não se tratar do melhor caminho a ser seguido por um clube, em virtude não só do risco de sua falência como também da eventual possibilidade de alienação de seus ativos tangíveis e intangíveis à terceiros, inclusive de outros Estados da federação ou até mesmo ao estrangeiro. Fato que traria um dano cultural irreparável aos indivíduos de uma dada localidade que, por ventura, praticassem ou torcessem pelo êxito esportivo daquele dado clube porque representava em sua origem a região de moradia de seus torcedores.

Diante dessa revelação, que pode até parecer um tanto quanto contraditória ao início de nosso discurso, eis então, a solução à carência e inabilidade de gestão dos clubes brasileiros, basta que ao invés de gerirem seus ativos, constituam uma pessoa jurídica para fazê-lo. Esta pessoa jurídica, a nosso ver, deve ser constituída sob a forma de empresário, daí à adoção da teoria da empresa. O que poderia até ser feito por meio de uma empresa individual, caso hodiernamente não tivéssemos impedimento legal para constituição de EIRELI ${ }^{11}$ por pessoa jurídica. Lamentavelmente, muito embora a Legislação Pátria não vede claramente a constituição da empresa individual de responsabilidade limitada (EIRELI) por pessoa jurídica, temos sua vedação imposta pelo Enunciado $n^{\circ} 468$, do Conselho da Justiça Federal e pela Instrução Normativa n ${ }^{\circ} 117 / 2011$, do Departamento de Registro do Comércio (DNRC). O que, inclusive, levou a Junta Comercial do Estado do Rio de Janeiro a adotar tal impedimento, conforme noticia no Informativo $\mathrm{n}^{\mathrm{o}} 60$, de junho de $2013^{12}$. A exploração de seus ativos como forma de angariar recursos para o clube por intermédio da EIRELI seria, sem dúvida alguma, para clubes pequenos a melhor forma de sua organização econômicofinanceira. Porém, diante da vedação legal, nada impede que a associação desportiva constitua uma sociedade empresária e sob as modalidades que melhor protejam o seu patrimônio pessoal,

\footnotetext{
${ }^{11}$ A EIRELI ou empresa individual de responsabilidade limitada está prevista no Código Civil de 2002 à partir do art. 980-A, que foi inserido pela Lei $\mathrm{n}^{\mathbf{0}} 12441 / 2011$ e representou um avanço para a pessoa que pretendesse exercer individualmente a atividade empresarial, porém sem o risco iminente de ser atingido o seu patrimônio pessoal conforme ocorre no caso do empresário individual.

${ }^{12}$ JUNTA COMERCIAL DO ESTADO DO RIO DE JANEIRO. Informativo JUCERJA n ${ }^{\mathbf{o}}$ 60/2013. Disponível no site: https://www.jucerja.rj.gov.br/Informativos/2013/Jucerja_60.pdf, retirado em 09.04.2016.
} 
considerando tratar-se de sociedades anônimas ou limitadas a depender de um quantitativo maior ou menor de recursos. Assim, será a partir desta premissa que iremos desenvolver o capitulo seguinte.

\section{Aplicação dos Institutos Utilizados a Partir da Teoria da Empresa aos Clubes.}

Conforme defendemos no capítulo anterior, uma saída adequada para a situação de crise econômico-financeira que alcança grande parte dos clubes brasileiros seria a criação de uma sociedade empresária. Pois, retiraria grande parte da responsabilidade de gestão do dirigente do clube e a traria para o administrador da referida sociedade, cujo preparo técnico é muito mais eficaz à gestão do negócio.

A definição de sociedade empresária surge no Ordenamento Jurídico Pátrio por meio do Código Civil Brasileiro de 2002. Sua previsão e definição legal é obtida ao conjugarmos os artigos 982, caput, e, 966, ambos do Código Civil. A partir destes dois artigos que podemos definir a sociedade empresária como sendo aquela que exerce a atividade economicamente organizada para produção e circulação de bens e serviços ${ }^{13}$. Entretanto, tal como fizemos no início deste artigo, é necessário darmos um paço atrás no sentido de entendermos o porquê dessa definição.

Em linhas gerais, o Código Civil Brasileiro de 2002 inovou ao incorporar em suas disposições parte do que era regulado pelo Código Comercial Brasileiro de 1850 e a razão desta incorporação ocorreu ante ao desejo do legislador pátrio, seguindo os passos de outros países, como a Itália em especial, de unificar o direito privado obrigacional. E, foi assim, que o Código Civil de 2002 trouxe em seu bojo à adoção da Teoria da Empresa. Teoria essa, que também serviu para reparar um problema existente no âmbito do Direito Comercial, que correspondia ao fato de não mais dar conta das novas espécies de atividades que surgiam e que por isso, permaneciam à margem de seu alcance e regulação. Assim, como solução para o referido problema foi incorporado ao texto legal do Código Civil de 2002 a teoria da empresa.

Concebida na Itália, por Alberto Asquini, a teoria da empresa substituiu a teoria dos atos de comércio anteriormente adotada no Brasil e se resumia na concepção de que a empresa seria o conceito de um fenômeno econômico poliédrico, o qual teria sob o aspecto jurídico, não um, mais diversos perfis, a saber:

\footnotetext{
${ }^{13}$ BRASIL. Código Civil Brasileiro. Lei no 10.406, de 10 de janeiro de 2002. Art. 966, caput.
} 
a) Perfil subjetivo, em que a empresa confunde-se com a figura do empresário. Isto é, a pessoa, física ou jurídica, que exerce a atividade economicamente organizada para produção ou circulação de bens ou serviços, nos termos do art. 966, do Código Civil.

Neste perfil, Asquini nos chama atenção para o fato de que "uma atividade econômica organizada" seria sinônimo de atividade empresarial, o que implicaria de parte do empresário a prestação de um trabalho autônomo de caráter organizador e a assunção do risco técnico $e$ econômico correlato ${ }^{14}$.

b) Perfil Patrimonial ou objetivo, em que a empresa é tida como o patrimônio e estabelecimento do empresário. Neste perfil, a empresa está associada ao complexo de bens e direitos que o empresário reúne para o exercício da atividade, incluindo-se inclusive o sobrevalor que tal reunião produz (fundo de comércio/azienda).

c) Perfil Corporativo, no qual a empresa é tida como uma instituição organizada pelo empresário e formada por ele, seus empregados e colaboradores, onde $a$ organização se realiza através da hierarquia das relações entre o empresário dotado de um poder de mando e os colaboradores ${ }^{15}$.

d) Perfil funcional, sob o qual a empresa confunde-se com a própria atividade a ser depreendida pelo empresário. E conforme explica Marlon Tomazette a empresa representaria um conjunto de atos tendentes a organizar os fatores da produção para a distribuição ou produção de certos bens ou serviços ${ }^{16}$.

Será a partir de uma análise detalhada de cada um destes perfis que Asquini irá concluir pela ausência de intenção de romper com a unidade do conceito de empresa existente como fenômeno econômico e consequentemente, como matéria de direito a empresa permanece a existir e viver como fenômeno econômico unitário. No entanto, todo o seu discurso foi no sentido de que para o direito a empresa deve ser sempre considerada e analisada sob os seus diversos perfis. Entendimento que foi internalizado pela doutrina brasileira, nas vozes de Marlon Tomazzete, José

\footnotetext{
${ }^{14}$ ASQUINI, Alberto. Profili dell'impresa. Rivista del Diritto Commerciale, 1943, v. 41, I. Tradução: COMPARATO, Fábio Konder. Perfis da Empresa. Revista de Direito Mercantil, Industrial, Econômico e Financeiro. São Paulo: Revista dos Tribunais, 1996. Nova série - Ano XXXV, n. 104. P. 114.

${ }^{15}$ Idem citação anterior, p. 122.

${ }^{16}$ TOMAZZETE, Marlon. Curso de Direito Empresarial. 5a Edição. São Paulo: Atlas, 2013. Vol. 1. P. 37
} 
Edwaldo Tavares Borba ${ }^{17}$, entre outros, porém sempre com a cautela de que a empresa fosse compreendida como atividade econômica organizada, não se confundindo nem com o sujeito exercente da atividade, nem com o complexo de bens por meio dos quais se exerce a atividade, que representam outras realidades ${ }^{18}$. Adiante, esclarece Marlon:

A empresa não possui personalidade jurídica, e nem pode possuí-la e, consequentemente, não pode ser entendida como sujeito de direito, pois ela é atividade econômica que se contrapõe ao titular dela, isto é, ao exercente daquela atividade. O titular da empresa é o que denominaremos de empresário ${ }^{19}$.

Assim, a partir do Código Civil de 2002 passamos a ter a figura do empresário, quer seja individual ou sociedade empresária, em quaisquer dos casos com personalidade jurídica própria e por sucedâneo lógico, direitos e obrigações também. Muito embora, encontremos no referido Código espécies societárias, sob as quais o empresário ou sociedade empresária ao se constituir, corra risco de comunicar os seus direitos e obrigações com as pessoas de seus constituidores, para fins deste trabalho, iremos desconsiderá-las. Vamos nos limitar a defender a utilização e constituição pelos clubes de sociedades empresárias das espécies limitada e Anônima, ante à redução do risco de comunicação das obrigações desta pessoa jurídica, ora constituída, à pessoa de seus constituidores.

Prevista no art. 1052 e seguintes, do Código Civil/02, a sociedade limitada é definida por Fran Martins como sendo aquela formada por duas ou mais pessoas, cuja responsabilidade é identificada pelo valor de suas quotas, porém todos se obrigam solidariamente em razão da integralização do capital social ${ }^{20}$. Desta definição, ou até mesmo em suas disposições legais prevista no Código Civil/02, obtemos o entendimento implícito de que esta espécie societária tanto pode ser constituída por pessoas físicas quanto jurídicas ante a ausência de vedação legal. Nesse aspecto, Fran Martins ao tratar da natureza jurídica de uma sociedade limitada vai dizer que nas sociedades limitadas temos sócios que tanto podem ser pessoas físicas ou jurídicas; apesar das doutrinas, o legislador teve em mente manter o hibridismo, de uma sociedade mista, tanto de

\footnotetext{
${ }^{17}$ Para quem: "A empresa é a atividade economicamente organizada, e o empresário é o agente dessa atividade, seja este uma pessoa natural ou uma pessoa jurídica”. (BORBA, José Edwaldo Tavares. Direito Societário. 14 ${ }^{\mathbf{a}}$ edição. São Paulo: Atlas, 2015. P. 14).

${ }^{18}$ TOMAZZETE, Marlon. Curso de Direito Empresarial. 5ª Edição. São Paulo: Atlas, 2013. Vol. 1, P.41.

${ }^{19}$ MESSINEO, Francesco. Manuale di diritto civile e commerciale. Milano: Giuffrè, 1957, vol. 1, p. 337. In apud TOMAZZETE, Marlon. Curso de Direito Empresarial. 5ª Edição. São Paulo: Atlas, 2013. Vol. 1, P.42.

${ }^{20}$ MARTINS, Fran. Curso de Direito Comercial. 39a edição. Rio de Janeiro: Forense, 2016.P. 211.
} 
capital quanto de pessoas $^{21}$. O que, em última análise, significa dizer que a sociedade limitada é uma espécie societária flexível, tanto por poder ser constituída por pessoa física ou jurídica assim como também, pelo fato de poder classificar-se como sendo uma sociedade de pessoas ou de capital. Se no caso da primeira, seria a limitada resvalada por diretrizes implícitas em suas cláusulas contratuais sob as quais as qualidades das pessoas de seus sócios seriam de grande valoração para sua constituição e manutenção da sociedade. Existe aqui, um caráter personalíssimo da pessoa do sócio para com a sociedade. Fato que repercute diretamente nos casos de cessão de quotas, falecimento ou ainda, penhora de quotas realizada por terceiros estranhos à sociedade. Já caso a sociedade limitada se constitua como uma sociedade de capital inexiste qualquer repercussão, tendo em vista ser indiferente quem quer que seja ou represente a figura do sócio, pois neste caso o que importa é o capital que o sócio trará para a sociedade. E finalmente, no que tange a essa espécie ou modelo de sociedade, ela pode ser constituída por documento particular ou escritura pública. Em quaisquer dos casos, deve a mesma submeter a registro na Junta Comercial do endereço de sua sede seus atos constitutivos. Trata-se de uma sociedade contratual, mas que pode optar por delinear-se nos casos de omissão legal sob os moldes de uma sociedade institucional, nos termos do que dispõe o parágrafo único do art. 1053, do Código Civil/02.

Mas, apesar de apontarmos a constituição de uma sociedade empresária de espécie limitada como sendo uma das opções a serem adotadas por um clube, entendemos que não seria esta a sua melhor opção, em virtude de possuir um risco maior que o da sociedade anônima de responsabilização patrimonial. Entretanto, mesmo com um risco maior de responsabilização a constituição de uma sociedade limitada por uma associação desportiva seria a mais aconselhável nos casos em que a associação seja carente de capital, uma vez que a sociedade anônima exige um volume maior de investimento, além de ser mais burocrática em sua constituição.

Agora passemos a explorar o que se apresenta como a melhor forma de constituição e exploração de seus ativos pelo clube, que é a constituição de uma sociedade empresária da espécie anônima. Prevista no Código Civil/02, nos artigos 1088 e 1089, a sociedade anônima possui Lei Especial para sua regulação de n 6404/76 também conhecida como "Lei de S/A". No que tange a sua definição, ela pode ser obtida tanto do art. 1088, do Código Civil/02 como do artigo $1^{\circ}$, da Lei nº 6404/76, e corresponde à sociedade empresária em que seu capital social se divide em ações, cuja

\footnotetext{
${ }^{21}$ Idem citação anterior. P 214.
} 
responsabilidade da cada sócio, também chamado de "acionista", estaria limitada pelo preço de emissão das ações que subscrever ou adquirir.

E, conforme explica Sérgio Campinho:

O anonimato, no qual se inspirou a denominação legal, resultou do fato de a sociedade não existir sob firma social, sendo-lhe obstado adotar essa modalidade de nome empresarial, que necessariamente indicará o nome de pelo menos um dos sócios ${ }^{22}$.

O direito a ter um nome trata-se de um dos direitos da personalidade aplicáveis à pessoa jurídica, de acordo com o que dispõe o art. 52, do Código Civil/02. E seguindo essa lógica, o nome empresarial está previsto no mesmo diploma legal a partir do art.1155, o qual estabelece as duas modalidades de constituição do nome empresarial, a saber: firma ou razão social e denominação. Em linhas gerais, as sociedades cujos sócios possuam responsabilidade ilimitada serão constituídas com o nome empresarial sob a forma de firma ou razão social, a fim de que a partir de seu próprio nome tenhamos publicizado e identificado às pessoas que a esta sociedade compõem. Além disso, a modalidade ou espécie de nome empresarial firma ou razão social não admite em sua constituição o "elemento fantasia". Ao passo que a outra modalidade de nome empresarial, chamada denominação, admite elemento fantasia para sua constituição e inadmite que para a sua constituição seja composta por nome das pessoas que a compõem. Ressalvando-se, apenas o caso de tal nome vir a ser utilizado como homenagem, nos termos do parágrafo único, do art.1060, do Código Civil/02.

É importante destacar, que transitam na utilização de qualquer uma das modalidades de nome empresarial as sociedades limitadas apesar de a responsabilidade dos sócios ser limitada ao valor do capital social a se integralizar, ante ao que dispõe o art. 1158, do Código Civil/02.

Ultrapassada a discussão a respeito do nome empresarial, o relevante é a cientificação de que a sociedade anônima faz uso da espécie "denominação" justamente porque a responsabilidade de seus acionistas é limitada à integralização do valor de emissão de subscrição ou aquisição de suas ações e uma vez feito isso, não há mais qualquer cobrança ou responsabilidade a ser arcada pelos mesmos. Daí, a defesa de ser essa a espécie de constituição de sociedade empresária mais adequada a ser adotada pelas associações desportivas e em nosso modelo-piloto, pelos clubes de futebol.

Além disso, agregado a tal argumento, temos ainda a possibilidade de a associação desportiva obter investimento junto ao público, por exemplo, para aquisição de um atleta ou treinador através da emissão de valores mobiliários. Obviamente, caso se constitua sob a forma de companhia aberta. Nesse aspecto, também seria possível a valorização ou não das ações de um 
clube face aos êxitos obtidos nos campeonatos. Enfim, a viabilidade pode ser constatada de múltiplas formas.

Em face desta constatação, seria possível que um clube por intermédio da constituição de uma sociedade empresária pudesse angariar investimento, provenientes dos lucros obtidos por esta última, por exemplo, advindos do registro, licenciamento ou da exploração do uso da marca, da negociação de um atleta, entre outros. E tudo isso, com o risco reduzido de lesão ao seu patrimônio. Contrariamente, ao que ocorre hoje.

Além disso, a associação desportiva não seria mais a vitima da crise. Seu abalo se resumiria na ausência de recebimento dos lucros e sequencialmente, na ausência de ampliação de investimentos em si. Mas, a sociedade empresária pela mesma constituída ao contrário, ao enfrentar tal crise poderia fazer uso dos institutos da falência da recuperação de empresas, ambas previstas na Lei $\mathrm{n}^{\circ} 11101 / 05$.

Esta lei representa uma verdadeira preocupação do legislador pátrio com a função social da empresa, propiciando a sua recuperação e nos casos mais graves a possibilidade de sobrevida ou manutenção do exercício da atividade por terceiros, ante à possibilidade de alienação de todo o seu ativo em blocos, conforme prevê o art. 140, inciso III, da Lei 11101/05. Mas que mesmo ao ser aplicada à sociedade empresária por um clube constituída não lhe agregaria riscos. Isso porque, seus principais ativos permaneceriam sob a propriedade da Associação, não podendo ser alcançados assim, pelos eventuais efeitos da falência. Um bom exemplo disso, é a exploração da Marca pertencente à associação desportiva, que apesar de explorada pela sociedade empresária por ela constituída, permanece sob a propriedade do clube, de modo a impedir que o valor cultural se desagregue. E por outro lado, na contramão da interpretação, permitindo que a associação desportiva, por intermédio da sociedade empresária pelo mesmo constituída, possa fazer uso do instituto da Recuperação, quer seja judicial ou extrajudicial, a depender do caso. É, inclusive, seguindo a visão ideológica deste artigo que o autor Eduardo Carlezzo vai defender a necessidade de criação de projetos de reestruturação societária para clubes de futebol, a saber:

Projetos de reestruturação societária que visem a modificar estruturas quase centenárias não podem prescindir da análise da situação dos clubes de futebol no Brasil e no exterior e do comportamento do mercado em relação ao futebol como negócio, para que, partindo-se de uma visão macroeconômica, possa se chegar as reais necessidades e possibilidades de entidade $^{23}$.

\footnotetext{
${ }^{23}$ CARLEZZO, Eduardo. Direito Desportivo Empresarial. São Paulo: Editora Juarez de Oliveira, 2004. P. 79.
} 
Enfim, esse foi o viés do presente trabalho no sentido de demonstrar a viabilidade de adoção da teoria da empresa e consequentemente, dos demais institutos existentes no Direito Empresarial Pátrio a fim de dar suporte aos clubes desportivos, pelo fato de serem estes os principais guardiães do direito fundamental ao desporto e em última análise, dos direitos fundamentais à vida e a saúde posto que contribui para o alcance ou manutenção destes últimos.

\section{CONCLUSÃO}

O respeito à vida e a melhoria em sua qualidade são fatores cruciais para o desenvolvimento humano e a prática de esportes está diretamente ligada a elas. Além disso, como se somente isto não fosse um bom motivo para exaltá-lo temos ainda, a sua eventual vinculação à cultura de uma nação. E diante disso, a sua proteção e seu incentivo torna-se um bem de valor incalculável. Motivo pelo qual, devemos criar meios de proteção e de superação das crises de seus maiores representantes, que são as associações para práticas desportivas - os clubes.

Conforme vimos, o empresário é dotado de características especiais que lhe propiciam a obtenção do lucro e, além disso, os institutos legais que o permeia possibilitam não só tal obtenção como também a superação de eventual crise. Com base em toda essa exposição, temos a percepção de que a transformação dos clubes em "empresa" seria a melhor forma de superação da crise sob a qual se encontram diversos clubes, em especial aqueles que incentivam como esporte à prática do futebol.

A adoção desta medida não só poderia sanar um problema de caixa como também traria melhores condições de vida a boa parte da população, quer seja pela incorporação da prática de esportes no seu dia-a-dia ou ainda, pela sua utilização como lazer ao fazer parte da torcida. E, como plus a toda esta benéfica situação teríamos ainda a possibilidade de melhor controle sob a gestão, ante ao risco e maior facilidade na imputação e adoção da teoria ultra vires.

\section{REFERÊNCIA BIBLIOGRÁFICA}

ALVES, Alexandre Ferreira de Assunção. A Pessoa Jurídica e os Direitos da Personalidade. Rio de Janeiro: Renovar, 1998.

ASQUINI, Alberto. Profili dell'impresa. Rivista del Diritto Commerciale, 1943, v. 41, I. Tradução: COMPARATO, Fábio Konder. Perfis da Empresa. Revista de Direito Mercantil, 
Industrial, Econômico e Financeiro. São Paulo: Revista dos Tribunais, 1996. Nova série - Ano XXXV, n. 104.

BASTOS, Celso. Justiça desportiva e defesa da ordem jurídica. Cadernos de Direito Constitucional e Ciência Política. São Paulo, vol. 6, nº 25. out/dez. 1998;

BRASIL Constituição da República Federativa do Brasil, de 05 de outubro de 1988. Disponível no site: http://www.planalto.gov.br/ccivil_03/Constituicao/Constituicao.htm, retirada em 08.04.2016;

Código Civil Brasileiro. Lei ${ }^{\circ} 10.406$, de 10 de janeiro de 2002. Disponível no site: http://www.planalto.gov.br/ccivil_03/leis/2002/110406.htm, retirado em 08.04.2016;

. Lei da Propriedade Industrial. Lei de $\mathrm{n}^{\circ}$ 9279, de 14 de maio de 1996. Disponível no site: http://www.planalto.gov.br/ccivil_03/leis/L9279.htm, retirado em 08.04.2016;

. Lei de Falência e Recuperação. Lei de nº 11.101, de 09 de fevereiro de 2005. Disponível no site: http://www.planalto.gov.br/ccivil_03/_ato2004-2006/2005/lei/111101.htm, retirado em 08.04.2016;

. Lei da Sociedade Anônima. Lei de no 6404, de 15 de dezembro de 1976. Disponível no site: http://www.planalto.gov.br/ccivil_03/leis/L6404consol.htm, retirado em 11.04.2016;

BRASIL. Lei $\mathbf{n}^{\mathbf{0}} \mathbf{9 . 6 1 5}$, de 24 de março de 1998. Disponível no site: http://www.planalto.gov.br/ccivil_03/leis/L9615consol.htm, retirado em 09.04.2016;

BORBA, José Edwaldo Tavares. Direito Societário. 14ª edição. São Paulo: Atlas, 2015;

CAMPINHO, Sérgio. Curso de Sociedade Anônima. Rio de Janeiro: Renovar, 2015;

CARLEZZO, Eduardo. Direito Desportivo Empresarial. São Paulo: Editora Juarez de Oliveira, 2004;

DELBIN, Gustavo. SILVA, Rodrigo Ferreira da Costa. GRAICHE, Ricardo. Elementos do Direito Desportivo. São Paulo: Quartier Latin, 2008; 
JUNTA COMERCIAL DO ESTADO DO RIO DE JANEIRO. Informativo JUCERJA n⿳0 60/2013. Disponível no site: https://www.jucerja.rj.gov.br/Informativos/2013/Jucerja_60.pdf, retirado em 09.04.2016;

MACHADO, Rubens Appobato. [el al]. Coordenadores. Curso de Direito Desportivo Sistêmico. São Paulo: Quartier Latin, 2010. Vol. II.

MARTINS, Fran. Curso de Direito Comercial. 39ª edição. Rio de Janeiro: Forense, 2016;

MIRANDA, Martinho Neves. O Direito no Desporto. Rio de Janeiro: Lumen Juris, 2007;

PAES, José Eduardo Sabo. Fundações, Associações e Entidades de Interesse Civil. $8^{\text {a }}$ Edição. Rio de Janeiro: Forense, 2013;

TOMAZZETE, Marlon. Curso de Direito Empresarial. 5a Edição. São Paulo: Atlas, 2013. Vol. 